\title{
Attitudes towards family planning in the Southeast Anatolian Project (SEAP) region of Turkey
}

Birgul Ozcirpici, Servet Ozgur, Saime Sahinoz, Ali Ihsan Bozkurt, Turgut Sahinoz, Ersen Ilcin, Gunay Saka, Ali Ceylan, Hamit Acemoglu, Yılmaz Palanci, Feridun Akkafa, Bayram Bektas, Ferit Karacasu, Mucide Ak

\section{Abstract}

Objective To determine attitudes towards family size and last pregnancies in order to improve family planning services in the Southeast Anatolian Project (SEAP) region.

Methods A questionnaire survey in the nine SEAP regional provinces was carried out under the auspices of the 'SEAP Public Health Project' from 2001 to 2002. The participants comprised 1756 women and 661 men from 1126 households.

Results For men and women aged 15 years and over the median ideal number of children was three. The rate of unintended last pregnancies $(43.1 \%)$ in the present study was very high compared to the national average of $18.8 \%$. Some $30.1 \%$ of the last pregnancies were unwanted by either partner.

Conclusions The number of pregnancies and children in this region is approximately twice as high as the ideal number. Families in the region are having more children than they want. Basic education must be given to women, particularly non-Turkish speakers, to improve their knowledge and use of family planning. Family planning education for men in rural areas also needs special attention.

J Fam Plann Reprod Health Care 2005; 31(2): 121-122 (Accepted 12 November 2004)

\section{Key message points}

- The number of pregnancies and the number of children is two times higher than desired in the SEAP region.

- The rate of unintended last pregnancies $(43.1 \%)$ is very high compared to the national average of $18.8 \%$, indicating a big gap in family planning services provision or take-up in the region.

- Family planning education needs, particularly those of men in rural areas, require special attention.

- Basic education must be given to women, particularly nonTurkish speakers, to improve their knowledge and use of family planning.

Department of Public Health, Faculty of Medicine, Gaziantep University, Gaziantep, Turkey

Birgul Ozcirpici, MD, Registrar

Servet Ozgur, MD, Registrar

Saime Sahinoz, MD, Registrar

Department of Public Health, Faculty of Medicine, Pamukkale University, Denizli, Turkey

Ali Ihsan Bozkurt, MD, Registrar

Medical Directorate of Gaziantep Province, Gaziantep, Turkey

Turgut Sahinoz, MD, Specialist in Public Health

Department of Public Health, Faculty of Medicine, Dicle

University, Diyarbakir, Turkey

Ersen Ilcin, PhD, Registrar

Gunay Saka, MD, Registrar

Ali Ceylan, MD, Registrar

Hamit Acemoglu, MD, Registrar

Yılmaz Palanci, MD, Registrar

Department of Medical Biology, Faculty of Medicine, Harran

University, Sanliurfa, Turkey

Feridun Akkafa, MSc, Registrar

Department of Parasitology, Faculty of Medicine, Ege

University, Bornova-Izmir, Turkey

Bayram Bektas, MD, Registrar

Ferit Karacasu, MD, PhD, Registrar

Mucide Ak, PhD, Registrar

Correspondence to: Professor Dr Servet Ozgur, Department

of Public Health, Faculty of Medicine, Gaziantep University

27310 Gaziantep, Turkey. Tel: +90 342 3603910/7757.

Fax: +90 342 3601617. E-mail: ozcirpici@gantep.edu.tr

\section{Objective}

The Southeast Anatolian Project (SEAP) project aims to collect data to help determine regional developmental inequalities in Turkey and covers the following provinces: Adıyaman, Batman, Diyarbakır, Gaziantep, Kilis, Mardin, Siirt, Sanliurfa and Sirnak. Public health issues and problems including those relating to reproductive health care are one of the main concerns of the project. Data were collected in order to determine attitudes to birth control, family size and unintended pregnancies in the SEAP region. It is hoped this will help promote appropriate strategies for family planning and better family planning services.

\section{Methods}

Setting and design

Study data were collected under the auspices of the 'SEAP Public Health Project' from 2001 to 2002. The project was supported by the SEAP Regional Development Management of the Central Ministry of the Republic of Turkey and conducted by a consortium comprising the Turkish Parasitology Association, Gaziantep University, Dicle University and Harran University.

The reproductive health data were obtained by a questionnaire survey conducted in the nine provinces of the SEAP region. Four questionnaires were developed (one each for men, women, household conditions and children aged 0-59 months) and covered household demographics, attitudes to family planning and reproductive health data.

The population size of the nine regional provinces is 6128973 , and a sample size of 6900 was determined to be sufficient to estimate proportions to within a $2 \%$ margin of error. This figure was divided by the average number of people per household (approximately six) giving the number of households per sample as 1150. Proportional sampling was used to represent both rural and urban areas of the region.

Trained survey teams, together with a public health specialist, visited all the households in the sample and completed the questionnaires during face-to-face interviews.

The data were evaluated using SPSS v.5.0 and Excel programmes. Chi-square $\left(\chi^{2}\right)$ test and logistic regression were used in the statistical analyses.

\section{Participants}

Of the 1150 households in the sample, 1126 were eligible for the survey. The questionnaires were completed by 1756 women and 661 men aged 15 years and over.

\section{Results}

In the region covered by the survey, $42.6 \%$ (748/1756) of the women were illiterate, $42.8 \%(751 / 1756)$ were in a consanguineous marriage and $92.5 \%(1625 / 1756)$ were housewives. Some 38.1\% (669/1756) could not speak Turkish. Their mean age at marriage was $17.4 \pm 3.2$ years and their mean age at first pregnancy was $18.4 \pm 3.2$ years. The mean total number of living children was $4.7 \pm 2.8$ overall and $6.5 \pm 2.6$ for women aged $45-49$ years.

The overall median ideal number of children was three for both women (mean, $3.4 \pm 1.5$ ) and men (mean, $3.8 \pm$ 2.2) aged 15 years and over. The median ideal number of children was four in rural areas (mean, $3.6 \pm 1.6$ for 


\section{ARTICLE}

women, $4.2 \pm 2.3$ for men) and three in urban areas (mean, $3.3 \pm 1.4$ for women, $3.4 \pm 2.0$ for men) for both women and men aged 15 years and over.

In May 1983, the Turkish Population Planning Law legalised the provision of abortion up to 10 weeks' gestation. As a result, safe medical terminations are now available for women in Turkey. Ever-married women (currently married, divorced, widowed) were asked what they would do if an unintended pregnancy occurred; $69.3 \%$ (854/1233) said that they would give birth to the child; $19.9 \%(245 / 1233)$ said that they would have an abortion; 9.7\% (119/1233) said they did not know what they would do and $1.2 \%(15 / 1233)$ said that their husband would decide. The percentage of women who said they would carry the unwanted pregnancy to term was higher in rural areas $(78.7 \%)(374 / 475)$ than in urban areas $(63.3 \%)$ (480/758). The percentage of women who said they would have an abortion was higher in urban areas $(27.3 \%)$ $(207 / 758)$ than in rural areas $(8.0 \%)(38 / 475)$. In total, $1.1 \%(5 / 475)$ of the women in rural areas said that their husband would decide compared to $1.3 \%$ (10/758) in urban areas and $12.2 \%(58 / 475)$ of the women in rural areas said that they don't know compared to $8.0 \%(61 / 758)$ in urban areas $\left(\chi^{2}=70.2\right.$, degrees of freedom $\left.=3, p<0.0001\right)$.

When asked about their last pregnancy, 30.1\% (353/1171) of the couples said this had been unwanted. This percentage was $32.1 \%(234 / 728)$ in urban areas and $26.9 \%(119 / 443)$ in rural areas. Some $56.9 \%(666 / 1171)$ of the last pregnancies were wanted by both partners. Interestingly, whilst a further $11.0 \%(129 / 1171)$ of the men wanted the last pregnancy but their partner did not, only a further $2.0 \%(23 / 1171)$ of the women wanted the pregnancy whilst their partner did not.

The total number of children the women already had also affected their wish for another child. Whilst 34.2\% (100/292) of the women who had two or fewer children did not want another child, this percentage rose to $70 \%$ (126/180) amongst the women who had three children and to $92.4 \%$ $(573 / 620)$ amongst women who had four or more children $\left(\chi^{2}=343.28\right.$, degrees of freedom $\left.=2, p<0.0001\right)$. A total of $73.2 \%(799 / 1092)$ of the women who had ever been pregnant did not want another child. This rate was similar in rural (74.4\%) (305/410) and urban (72.4\%) (494/682) areas.

Logistic regression analysis demonstrated that ethnic origin and total number of living children were the main factors affecting the women's wish for another child (Table 1). Being a Turkish speaker and the total number of living children were the main factors affecting the women's attitude towards their last pregnancy (Table 2).

\section{Discussion}

The mean ideal number of children for women and men aged 15 years and over $(3.4 \pm 1.5$ for women and $3.8 \pm 2.2$ for men) in the SEAP region is similar to that in the East Anatolian region ${ }^{1}$ (with a mean of 3.1 for women and 4.0 for men); but these rates are higher than those for Turkey as a whole (with a mean of 2.5 for women and 2.7 for men). ${ }^{1}$ In rural areas, the ideal number of children was higher than in urban areas both for women and men.

Though the ideal number of children was found to be 3.4 in the region studied, the average number of total pregnancies was 6.4 and the average number of living children was 4.7 amongst women who have ever been pregnant. Therefore, the pregnancy rate and number of children is approximately two times higher than desired.

The TDHS-1998 found that $18.8 \%$ of births over the
Table 1 Factors predicting the likelihood of wanting another child (logistic regression analysis)

\begin{tabular}{lccc}
\hline Independent variables & \multicolumn{3}{c}{ Status of wanting another child } \\
\cline { 2 - 4 } & $p$ & OR & $95 \%$ CI \\
\hline Ethnic origin & & 1 & 1 \\
$\quad$ Turkish & $<0.0001$ & 3.01 & $2.06-4.39$ \\
Kurdish & $<0.0001$ & 5.79 & $2.74-12.24$ \\
Arabic & 0.010 & 4.54 & $1.43-14.41$ \\
Zaza & $<0.0001$ & 0.40 & $0.35-0.46$ \\
Total number of living children &
\end{tabular}

CI, confidence interval; OR, odds ratio.

Table 2 Factors predicting whether the last pregnancy was wanted (logistic regression analysis)

\begin{tabular}{lccc}
\hline Independent variables & \multicolumn{3}{l}{ Status of wanting the last pregnancy } \\
\cline { 2 - 4 } & $p$ & OR & $95 \%$ CI \\
\hline Knowledge of Turkish & & 1 & 1 \\
$\quad$ None & 0.439 & 1.12 & $0.84-1.51$ \\
Speaks a little & $<0.0001$ & 2.34 & $1.55-3.52$ \\
Fluent & $<0.0001$ & 0.83 & $0.79-0.87$ \\
Total number of living children &
\end{tabular}

CI, confidence interval; OR, odds ratio.

last 5 years in Turkey were unintended. ${ }^{1}$ By comparison, the rate of unintended last pregnancies $(43.1 \%)$ in the present study is very high, indicating a big gap in family planning services provision or uptake in the region.

As mentioned previously, whilst $11.0 \%$ (129/1171) of the men wanted the last pregnancy, only $2.0 \%(23 / 1171)$ of the women were of the same opinion and $30.1 \%$ of the last pregnancies were not wanted by either partner. In an intervention study conducted in rural areas of Gaziantep, family planning education provided for men was found to be as effective as education provided for women. ${ }^{2}$ This suggests that attention should be given to men's family planning education needs as well as those of women in the region.

The present results show that $49.7 \%$ of women who have two living children, $70 \%$ of those who have three living children and $92.4 \%$ of those who have four or more living children do not want another child. Appropriate education and family planning services must now be provided to help them achieve this aim.

Ethnic origin and being a Turkish speaker were the main factors affecting attitudes towards family planning. The educational level of women who cannot speak Turkish was low; thus, basic education must be given to these women before they can undertake family planning education.

A woman who cannot control her own fertility effectively cannot be completely physically, mentally and socially healthy. All health service personnel must ensure that they can deliver accessible, acceptable and integrated health care so that the barriers to effective family planning can be reduced.

Statements on funding and competing interests

Funding. This study was supported by the SEAP Regional Development Management of the Central Ministry of the Republic of Turkey. Competing interests. None identified.

References

1 Hacettepe University Population Research Institute, MEASURE DHS + Macro International Inc. and UNFPA. Turkish Demographic and Health Survey (TDHS) 1998 [in Turkish]. Ankara, Turkey: Hacettepe University, Population Research Institute, 1999.

2 Ozgur S, Bozkurt AI, Ozcirpici B. The effects of family planning education provided to different gender groups. Br J Obstet Gynaecol 2000; 107: 1226-1232. 